\title{
Urban as a Determinant of Health
}

\author{
David Vlahov, Nicholas Freudenberg, Fernando Proietti, \\ Danielle Ompad, Andrew Quinn, Vijay Nandi, \\ and Sandro Galea
}

\begin{abstract}
Cities are the predominant mode of living, and the growth in cities is related to the expansion of areas that have concentrated disadvantage. The foreseeable trend is for rising inequities across a wide range of social and health dimensions. Although qualitatively different, this trend exists in both the developed and developing worlds. Improving the health of people in slums will require new analytic frameworks. The social-determinants approach emphasizes the role of factors that operate at multiple levels, including global, national, municipal, and neighborhood levels, in shaping health. This approach suggests that improving living conditions in such arenas as housing, employment, education, equality, quality of living environment, social support, and health services is central to improving the health of urban populations. While social determinant and multilevel perspectives are not uniquely urban, they are transformed when viewed through the characteristics of cities such as size, density, diversity, and complexity. Ameliorating the immediate living conditions in the cities in which people live offers the greatest promise for reducing morbidity, mortality, and disparities in health and for improving quality of life and well being.
\end{abstract}

KEYWORDS Slums, Social determinants, Urban health, Urbanization.

\section{URBANIZATION IN A GLOBAL CONTEXT}

Reconciling the growing proportion of the global population that lives in urban centers with the goal of creating healthy cities for all poses the major public health challenge of the 21st century. In this century, urban change is predicted in three directions. First, more people will move into urban centers, a process called urbanization that will result in an ever-growing proportion of the global population living in urban areas. Second, slums will become home to a higher proportion of the world's poor, with profound implications for population health. Third, cities will spread spatially with dramatic effects on the environment and human health.

A recent report about the growth of urban populations from the United Nations Population Division notes that half of the world's population now lives in urban areas, and within the next 30 years, nearly two-thirds of the world's population will live in urban areas. ${ }^{1}$ In addition, most of the world's population

\footnotetext{
Vlahov, Ompad, Quinn, Nandi, and Galea are with the Center for Urban Epidemiologic Studies, New York Academy of Medicine, New York, NY, USA; Freudenberg is with the Hunter College, City University of New York, New York, NY, USA; Proietti is with the Departamento de Medicina Preventiva e Social, Faculdade de Medicina, Universidade Federal de Minas Gerais, Belo Horizonte, Minas Gerais, Brazil; Galea is with the Department of Epidemiology, School of Public Health, University of Michigan, Ann Arbor, MI, USA.

Correspondence: David Vlahov, Center for Urban Epidemiologic Studies, New York Academy of Medicine, New York, NY, USA. (E-mail: dvlahov@nyam.org)
} 
growth in this period is expected in urban areas in less wealthy regions of the world (growth from 1.9 billion in 2000 to 3.9 billion in 2030), with the most rapid pace of growth expected to occur in Asia and Africa. ${ }^{2,3}$ For example, the number of urban dwellers in the least urbanized region, Asia (1.4 billion), is already greater than the urban population in North America and Europe combined (1.2 billion) in 2000. ${ }^{4,5}$

Urban growth is expected to occur more slowly in megacities and faster in midsized cities. ${ }^{6}$ The proportion of people living in megacities (cities with populations greater than 10 million) is expected to rise from $4.3 \%$ of the global population in 2000 to $5.2 \%$ in 2015 . The growth rate of megacities in the developing world will be much higher than in the developed world (e.g., anticipated growth from 2000 to 2015 in Calcutta is $1.9 \%$ vs. New York City, 0.4\%). In 1975, only five cities worldwide had 10 million or more inhabitants, of which three were in developing countries. The number will increase to 23 by 2015, with all but four of them in developing countries. Also, by 2015 an estimated 564 cities around the world will contain one million or more residents. Of these, 425 will be in developing countries. However, while large cities of developing countries will account for $20 \%$ of the increase in the world's population between 2000 and 2015 , small cities (less than five million) will account for $45 \%$ of this increase. ${ }^{4}$ Thus, a growing number of relatively small cities throughout the world will contain most of the world's population in the 21 st century while a few megacities will undoubtedly face unique challenges. These projections highlight the importance of viewing urban health as an international and global issue.

The higher rate of urban growth in developing countries is related mostly to economic engines. In developing countries, the largest cities are concentrated in the largest economies: Brazil and Mexico in Latin America and China, India, Indonesia, and the Republic of Korea in Asia. There are also some cities in other regions (e.g., sub-Saharan Africa) where movement occurs despite economic stagnation and in others whose population is increased by the movement there of people displaced by wars, civil strife, or drought, but this is usually a temporary movement, not a permanent one. ${ }^{7,8}$

\section{GROWTH OF SLUMS WITH URBANIZATION IN THE DEVELOPING WORLD}

In the developing world, where most of the global urbanization is to be observed, a large segment of that growth is into slums. ${ }^{9,10}$ The definition of "slum" used by UNHabitat includes "a wide range of low-income settlements and/or poor human living conditions." 8 Taken alone, this definition inadequately captures the very diverse kinds of housing used by low-income groups (tenements, cheap boarding houses, squatter settlements, houses built on illegal subdivisions) but it represents a short hand for an area of concentrated disadvantage. Slums are further characterized by the following attributes: (a) lack of basic services, (b) substandard housing or illegal and inadequate building structures, (c) overcrowding and high density, (d) unhealthy living conditions and hazardous locations, (e) insecure tenure and irregular or informal settlements, (f) poverty and social exclusion, and (g) minimum settlement size. ${ }^{8,9}$

Estimating the number of slum dwellers is difficult because data from urban populations, especially in developing countries, may not include slum residents as they may not be recognized legally, they might be homeless, they might move 
frequently, they might not be included in censuses, or they may not live within city borders. ${ }^{11}$ With this acknowledged, according to the latest Global Report on Human Settlements, ${ }^{9}$ some $923,986,000$ people, or $31.6 \%$ of the world's total urban population, live in slums; some $43 \%$ of the urban population of all developing regions combined live in slums; some $78.2 \%$ of the urban population in the least developed countries live in slums; and some $6 \%$ of the urban population in developed regions live in slum-like conditions. The total number of slum-dwellers in the world increased by about $36 \%$ during the 1990 s, and in the next 30 years, the global number of slum dwellers will increase to about two billion and, in 50 years, to three billion if no concerted action to address the challenge of slums is taken. In most African cities, between 40 and $70 \%$ of the population live in slums or squatter settlements. In a city like Nairobi, $60 \%$ of the population lives in slums, which occupy about $5 \%$ of the land. ${ }^{12}$ The growth of slums poses monumental challenges to urban health in specific and global health as a whole.

\section{URBANIZATION, DEVELOPMENT, SLUMS, AND HEALTH}

Urbanization has been traditionally linked to development and development with health, but in the face of development is the growth of slums, which are linked with poor health. Two common measures of urbanization that use publicly available WHO data ${ }^{13-15}$ are percent urban, i.e., that which is already urbanized, and urbanization expressed here as the rate of change, e.g., a rate of increase (or decrease) in a country's level of urbanization. The validity of most of the generalizations about "level of urbanization" and other indicators is limited by the very large differences in the criteria used by different governments to define their urban population. With this caveat acknowledged, these measures are negatively correlated with each other when data on different countries are combined, that is, rates of urbanization are lower in areas already highly urbanized. Within countries, a number of studies have shown that health outcomes are worse in slums than in surrounding (or adjacent) urban areas, in the district, or in the nation overall. ${ }^{16-24}$ The WHO estimates the proportion of "urban percent slum," i.e., the vulnerable populations in areas of concentrated disadvantage within each country. Urban percent slum is negatively associated with "percent urban" and positively associated with "urbanization." Turning our attention to a particular health indicator, infant mortality shows a negative (or possibly protective) association with percent urban, but a positive (increased) association with (the rate of) urbanization. Also, there is a strong positive association between infant mortality rates and "slums as percent urban."

The direct relationship of urbanization with infant mortality (and the inverse association of "percent urban" with this outcome) might be explained by measures of development such as the measure of the gross national income (GNI) per capita or the gross domestic product (GDP). When the world is divided into low-, lowmiddle-, high-middle-, and high-income countries, there is a positive association between GNI and "percent urban" that shows that cities are associated with development. In a combined model ( $n=154$ countries), GNI and percent urban are each inversely associated with infant mortality independent of the other, suggesting some advantage for urban residents.

However, when looking at infant mortality by GNI and the variable, urban percent slums, results show that the former is inversely while the latter is positively associated 
with mortality; as important, the two variables are statistically independent. An overall inference that can be suggested from these simple analyses is as follows: while cities are associated with development (and development with positive health outcomes), areas of concentrated disadvantage in cities show worse outcomes irrespective of level of development. Replacing GNI with GDP demonstrated similar results.

\section{LIVING CONDITIONS AS DETERMINANTS OF URBAN HEALTH}

The preceding section highlights the health inequity associated with slums. A socialdeterminants approach to health takes these observations a step further and emphasizes improving living conditions in such arenas as housing, employment, education, equality, quality of living environment, diet, social support, and health services. To assess the impact of several key determinants of health, ${ }^{25}$ we find it useful to consider four broad categories that may frame questions on how city living can affect health-population composition, the physical environment, the social environment, and availability of and access to health and social services. We discuss each of these briefly here and refer the reader to other published work that discusses each of these in more detail. ${ }^{26}$ These urban characteristics vary widely within and between cities in the North and South; they can be viewed as the "conditions" that public health interventions seek to change.

Population composition The demographic characteristics of who is living in a particular city or urban neighborhood at a particular time reflect historical trends, patterns of fertility, in-migration (movement within national boundaries) and immigration (movement across national boundaries). Virtually all urban centers also have major out-migration flows too, which also influence their population composition. Even cities that are growing rapidly have diverse out-migration (although obviously with the scale of in-migration exceeding the scale of outmigration). Characteristics of populations that influence health are age and gender distribution, genetic characteristics, health beliefs, and cultural attitudes. While the diversity of urban populations ensures that there is no urban genotype, genetic characteristics interact with environmental conditions to produce urban phenotypes with particular health resiliencies and vulnerabilities. Changes in urban population composition over time as a consequence of urbanization, immigration, aging, and fertility decline have a profound impact on health. ${ }^{27-29}$

Physical environment The relevant features of the physical environment that are particularly important to urban areas include access to safe drinking water, sanitation, drainage, and garbage collection; also important are air and noise pollution and the built environment. ${ }^{30}$ Especially important from a health perspective are the pathogens and vectors associated with high levels of infectious and parasitic diseases, including diarrheal diseases, intestinal parasites, and "waterwashed" diseases. Providing access to safe water, garbage removal, and sanitation in the late 19th and early 20th centuries created the conditions for the dramatic reductions in mortality from infectious diseases in developed nations; ${ }^{31}$ now cities in developing nations face these same challenges. ${ }^{15,32-34}$ Hazardous waste landfill sites are often located in or near urban areas or, in the case of slums in developing countries, may be the land on which housing is built; these landfills may be 
associated with risks of low birth weight, birth defects, infectious diseases, and cancers. ${ }^{35}$ In terms of air pollution, the developed and developing worlds differ in terms of types and concentrations of pollutants, especially with differences in indoor pollution. ${ }^{36}$ Environmental particulate matter has been associated with cardiovascular death and asthma. ${ }^{37,38}$ Noise exposure, a common urban problem, may be associated with hearing impairment, hypertension, and ischemic heart disease. ${ }^{39}$ The built environment also influences health. ${ }^{40,41}$ Inadequate, overcrowded, or deteriorating housing or informal settlements, especially where tenure is insecure (i.e., makeshift, tenements, or cheap boarding houses), is associated with injuries, respiratory problems, infectious diseases, and mental health problems. ${ }^{21,22,24,42}$ Poor transportation inhibits access to employment and health services; poor work conditions lead to injuries. Another determinant of health is access to and sufficient quantities of safe and quality food. ${ }^{18}$ Another aspect of the physical environment is climate and geography, and the vulnerability to natural disasters including cyclones, floods, earthquakes, landslides, fires, and industrial accidents. ${ }^{6}$ This topic is further addressed in another paper in this issue. ${ }^{43}$

Social environment The social environment describes the structure and characteristics of relationships among people within a community. Components of the social environment include social networks, social capital, and the social support that interpersonal interactions provide. A comprehensive definition of many of these factors is given elsewhere ${ }^{44}$ and is addressed more fully in other papers in this volume. $^{45,46}$ The social environment influences health through a variety of pathways, including the support of individual or group behaviors that affect health, buffering or enhancing the impact of stressors, and providing access to goods and services that influence health (e.g., housing, food, informal health care). ${ }^{47}$ A city's social environment can support or damage health. ${ }^{16,17,23}$ Positive urban features include higher levels of social support and the presence of organizations that can act to improve living conditions. Social support has been shown to contribute to a variety of positive health outcomes. ${ }^{20}$

Problematic characteristics of the urban social environment may include social support for health damaging behavior (e.g., drugs, gangs) and high levels of social stressors such as social isolation, violence, and extreme poverty. ${ }^{48-50}$ The concentration of poverty leads to social exclusion, which can reduce the availability of social support and access to health and social services.

Health and social services Cities are characterized by a rich array of health and social services in comparison to outlying areas. Even the poorest urban neighborhood often has social agencies, each with a distinct mission and service package. ${ }^{51}$ Their organizational lifespan may be short, the funding inadequate, the quality of services uneven, and the coordination with other providers limited, but these assets provide an important resource for health. The situation in slums in most developing countries is more complex because of the illegal status and, therefore, absence of emergency or other formal services. Slums may have fewer formal services than better-off urban neighborhoods but may include a variety of informal and self-help groups. ${ }^{52}$

Upstream influences on living conditions Living conditions shape health but are also influenced by municipal, national, and international trends. Municipal factors include government, markets, and civic society. 
Government Government influences the health of urban populations by providing municipal services, regulating activities that affect health, and setting the parameters for urban development. Government policies can exacerbate or reduce social inequality and support living conditions that promote or damage health. Government activities in many sectors affect health, including those in public education, public transportation, public safety, criminal justice, welfare, housing, and employment. Public transportation and the municipal regulation of private transportation offers one example of how municipal services in nonhealth arenas can affect health. Public transportation can facilitate population mobility in densely populated urban areas, increasing access to education, employment, and stores that sell fresh foods and vegetables. Effective traffic management speeds the delivery of emergency medical services.

The issue of "illegality" in most of the "slums" in low- and middle-income nations inhibits public service provision and accentuates the influence of "bad governance." This lack of legal recognition of slums means not only the absence of basic services, such as water, sanitation, garbage removal, health care services, but also the absence of health surveys and even a census on which to document the extent of the need. Approaches to this have included self-organization of slum dwellers and partnerships with nongovernmental advocacy groups to seek recognition, status, and services.

An extensive literature shows that good governance is an important determinant of urban health. ${ }^{19,53,54}$ Conversely, some have suggested that poor global, national, and municipal governance is a major cause of the global growth of slums. ${ }^{52,55}$ Effective and representative government, including the institutional means to ensure provision of an infrastructure and services and the control of pollution, are necessary to address urban health problems effectively. ${ }^{30}$ Examples from different cities demonstrate what can be achieved. People in the city of Porto Alegre in Brazil, known for its participatory budgeting (which allows citizens to influence public investment priorities in their neighborhood) have a life expectancy of 76 years. ${ }^{56}$ Small cities such as Ilo in Peru and Manizales in Colombia have shown how much local initiatives can improve health and living standards. ${ }^{57,58}$ Thus, governments and international agencies should look to the institutional means needed to ensure that this happens. This topic of good governance is addressed in more detail in other papers of this volume. ${ }^{59}$

Markets In early human history, the density of urban populations and the resulting specialization of labor created the conditions for markets. ${ }^{60}$ As a method of allocating scarce resources, markets are a quintessentially urban form. Today, local and global markets play a central role in shaping the conditions that determine the health of urban populations. Markets allocate housing, food, medical care, and transportation and increasingly play a role in education, public safety, and other sectors previously confined to the public realm. In addition, markets play a role in undermining health by making tobacco, illicit drugs, alcohol, obesogenic food, firearms, unsafe and polluting cars, and other products available to the urban rich and poor. ${ }^{61}$ Markets have also played a key role in promoting the lifestyles associated with the growth of chronic diseases. ${ }^{62}$

Civic society Civic (or civil) society defines the space not controlled by government or the market where residents interact to achieve common goals. While these three 
sectors are conceptually distinct, in practice they work together intimately. In the last decade, politicians from both the left and right, as well as academics from several disciplines, have debated its role, whether it is contracting or expanding and its influence on health. ${ }^{63}$ Related concepts include social capital, social cohesion, social support, community capacity, and community competence.

Several participants in civic society can influence the health of urban populations. Community-based organizations, such as neighborhood associations and tenant groups provide services, mobilize populations and advocate for resources. Churches and faith-based organizations offer social support, safe space, and political leadership. ${ }^{64-66}$ In both developed and developing world cities, organizations representing residents of slums, poor people, or marginalized groups can bring new voices into the political arena and mobilize for improved living conditions. ${ }^{67}$ In addition, social movements struggle for institutional and policy change. The state of civil society in a community at a given time can influence its ability to protect the health of residents; promote social cohesion; and counter isolation, stigma, or marginalization. For urban health researchers, finding ways to measure the state of civil society ${ }^{66}$ and analyze its impact on specified health outcomes is an important task.

Living conditions influenced by municipal factors are further influenced by national and international trends such as immigration, urbanization, and globalization. These other influences are described and addressed by related papers.

Social determinants in the urban setting While social determinant and multilevel perspectives are not uniquely urban, they provide unique insights into defining urban characteristics of cities such as size, density, diversity, and complexity. ${ }^{68,69}$ This has implications for developing interventions to improve health in cities.

First, urban areas are characterized by population density and diversity. While density is considered as crowding and, therefore, enhancing transmission of infectious diseases, in fact, density also enables public health programs to reach large sectors of the population efficiently. Diversity increases a cultural richness in cities but can also lead to cultural clashes; diversity necessitates tailoring interventions to meet the needs of different subpopulations. Finding the right balance between these competing pressures of density and diversity is a constant challenge for planners of urban health interventions.

Second, compared with other areas, cities have a rich array of social and human resources, from dense social networks and many community organizations to numerous formal and informal service providers. These human resources and the social capital inherent within them constitute key assets for intersectoral urban health promotion and may make it easier to operate in multiple sectors, even with limited resources. Effective public health programs use these assets both to root interventions in a specific urban context and to reduce the need for external resources. Finding the right assets, mobilizing them, and ensuring their sustainability are important tasks for urban health interventionists. Providing adequate external support to capitalize on these strengths presents a continuing challenge for developed nations and international organizations.

Third, cities are complex. Multiple systems interact; pluralistic political structures create competing stakeholders; and cities are inextricably linked to other sociopolitical levels, such as neighborhoods, metropolitan regions, and nationstates, each of which makes demands and offers resources to the other levels, and 
local political and social forces create wide variations in the contexts in which programs are delivered. As a result, simple interventions are rarely sufficient to solve problems; many programs have unintended, as well as intended, outcomes; and generalization from one setting to another can be problematic. This contextual complexity requires a similar level of intervention complexity-a defining characteristic of intersectoral approaches.

Fourth, because most cities are characterized by high levels of inequality, interventions - even beneficial ones - run the risk of reinforcing or even widening disparities in health. Helping everyone get more of the necessities of life often further advantages the better-off individuals. To avoid this unintended effect, urban public health planners need to define disparity reduction as an explicit goal. Because intersectoral interventions can work across the many sectors that contribute to disparities, they may be better able to make disparity reduction a priority.

Finally, city governments and urban populations have limited resources to face multiple problems (e.g., in education, employment, crime prevention, environmental protection, and sanitation). Investment in these areas will be key to improving the health of populations. Related to this is the priority for municipal governments to demonstrate intersectoral approaches within their agencies and to assemble the coalitions and political support needed to sustain their interventions.

In summary, urban health interventions differ from interventions in other settings both because urban populations present a different health profile and because the urban environment is markedly different from suburban or rural ones. To be successful, public health interventionists must address both types of differences. Effective public health programs must use available scientific evidence to meet the unique needs of urban populations and a thorough understanding of the relevant social and political contexts to manage the process of program implementation and institutionalization. Intersectoral approaches may help to overcome these daunting challenges.

\section{REFERENCES}

1. United Nations. World Urbanization Prospects: The 2003 Revision. United Nations; 2004. http://esa.un.org/unup/. Cited 26 February 2007.

2. Brockerhoff M. An urbanizing world. Popul Bull. 2000;55(3):3-4.

3. McCord C, Freeman HP. Excess mortality in Harlem. N Engl J Med. 1990;322(3): 173-177.

4. Bureau of the Census. Population Reports 2001. U.S. Census Bureau; 2006. http:// www.census.gov/. Cited 26 February 2007.

5. Wakabayashi K. Migration from rural to urban areas in China18. Dev Econ. 1990;28(4):503-523.

6. Satterthwaite D. Will most people live in cities? BMJ. 2000;321(7269):1143-1145.

7. Hardoy JE, Satterthwaite D. Urban change in the third world: are recent trends a useful pointer to the urban future? Habitat Int. 1986;10(3):33-52.

8. United Nations Centre for Human Settlements. An Urbanizing World: Global Report on Human Settlements, 1996. New York: Oxford; 2007.

9. UN Habitat. The Challenge of Slums-Global Report on Human Settlements 2003. London: Earthscan; 2003.

10. Ooi G, Phua KH. Urbanisation and slum formation. J Urban Health. 2007; in press.

11. Montgomery MR, Stren R, Cohen B, Reed H. Cities Transformed: Demographic Change and Its Implcations in the Developing World. Washington, DC: The National Academies Press; 2003. 
12. Alder G. Tackling poverty in Nairobi's informal settlements: developing an institutional strategy. Environ Urban. 1995;7(2):85-108.

13. CIA. The World Factbook. CIA; 2006. https://www.cia.gov/cia/publications/factbook/ index.html. Cited 7 September 2006.

14. United Nations. World Urbanization Prospects: The 2005 Revision Population Database. United Nations; 2006. http://esa.un.org/unup/. Cited 26 February 2007.

15. World Health Organization. Global Health Atlas. World Health Organization; 2006. http://globalatlas.who.int/. Cited 26 February 2007.

16. Freudenberg N. Health promotion in the city: a structured review of the literature on interventions to prevent heart disease, substance abuse, violence and HIV infection in U.S. metropolitan areas 1980-1995. J Urban Health. 2000;77(3):443-457.

17. Geronimus AT. To mitigate, resist, or undo: addressing structural influences on the health of urban populations. Am J Public Health. 2000;90(6):867-872.

18. Ghosh S, Shah D. Nutritional problems in urban slum children. Indian Pediatr. 2004;41(7):682-696.

19. Guerra FA, Crockett SA. Overcoming the hurdles to providing urban health care in the 21st century. Acad Med. 2004;79(12):1148-1153.

20. Hawkins JD, Catalano RF, Miller JY. Risk and protective factors for alcohol and other drug problems in adolescence and early adulthood: implications for substance abuse prevention. Psychol Bull. 1992;112(1):64-105.

21. Katsivo MN, Mwaura LW, Muniu E, Amuyunzu M. Accidents involving adults in the home environment in Nairobi, Kenya. East Afr Med J. 1994;71(6):350-353.

22. Krieger J, Higgins DL. Housing and health: time again for public health action. Am J Public Health. 2002;92(5):758-768.

23. Leviton LC, Snell E, McGinnis M. Urban issues in health promotion strategies. Am J Public Health. 2000;90(6):863-866.

24. Sharma S, Sethi GR, Rohtagi A, et al. Indoor air quality and acute lower respiratory infection in Indian urban slums. Environ Health Perspect. 1998;106(5):291-297.

25. WHO Centre for Health Development. A Billion Voices: Listening and Responding to the Health Needs of Slum Dwellers and Informal Settlers in New Urban Settings. World Health Organization; 2005. http://www.who.or.jp/network.html. Cited 26 February 2007.

26. Freudenberg N. Interventions to improve urban health. In: Freudenberg N, Galea S, Vlahov D, eds. Cities and Health of the Public. Nashville, TN: Vanderbilt University Press; 2006:294-326.

27. Auchincloss AH, Hadden W. The health effects of rural-urban residence and concentrated poverty. J Rural Health. 2002;18(2):319-336.

28. Jackson AA. Integrating the ideas of life course across cellular, individual, and population levels in cancer causation. J Nutr. 2005;135(Suppl 12):2927S-2933S.

29. Ostir GV, Eschbach K, Markides KS, Goodwin JS. Neighbourhood composition and depressive symptoms among older Mexican Americans. J Epidemiol Community Health. 2003;57(12):987-992.

30. Hardoy J, Mitlin D, Satterthwaite D. Environmental Problems in an Urbanizing World: Finding Solutions for Cities in Africa, Asia, and Latin America. London: Earthscan; 2001.

31. Sheard S, Powers H. Body and City: Histories of Urban and Public Health. Aldershot: Ashgate; 2000.

32. Moe CL, Rheingans RD. Global challenges in water, sanitation and health. J Water Health. 2006;4(Suppl 1):41-57.

33. Lundqvist J, Appasamy P, Nelliyat P. Dimensions and approaches for Third World city water security. Philos Trans R Soc Lond B Biol Sci. 2003;358(1440):1985-1996.

34. Hamner S, Tripathi A, Mishra RK, et al. The role of water use patterns and sewage pollution in incidence of water-borne/enteric diseases along the Ganges river in Varanasi, India. Int J Environ Health Res. 2006;16(2):113-132. 
35. Vrijheid M. Health effects of residence near hazardous waste landfill sites: a review of epidemiologic literature. Environ Health Perspect. 2000;108(Suppl 1):101-112.

36. Bradley D, Stephens C, Harpham T. A Review of Environmental Health Impacts in Developing Country Cities, Urban Management Discussion Paper No. 6. Washington, DC: World Bank Publications; 1991.

37. Benicio MH, Ferreira MU, Cardoso MR, Konno SC, Monteiro CA. Wheezing conditions in early childhood: prevalence and risk factors in the city of Sao Paulo, Brazil. Bull World Health Organ. 2004;82(7):516-522.

38. Dominici F, Peng RD, Bell ML, et al. Fine particulate air pollution and hospital admission for cardiovascular and respiratory diseases. JAMA. 2006;295(10):1127-1134.

39. Passchier-Vermeer W, Passchier WF. Noise exposure and public health. Environ Health Perspect. 2000;108(Suppl 1):123-131.

40. Comaru FA, Westphal MF. Housing, urban development and health in Latin America: contrasts, inequalities and challenges. Rev Environ Health. 2004;19(3-4):329-345.

41. Diez Roux AV. Residential environments and cardiovascular risk 27. J Urban Health. 2003;80(4):569-589.

42. Guerra FA, Crockett SA. Overcoming the hurdles to providing urban health care in the 21st century. Acad Med. 2004;79(12):1148-1153.

43. Kjellstrom T, Freil S, Dixon J, et al. Urban environmental health hazards and health equity. J Urban Health. 2007; in press.

44. Berkman LF, Kawachi I. Social Epidemiology. New York: Oxford; 2000.

45. Ompad D, Galea S, Caiaffa W, Vlahov D. Social determinants of the health of urban populations: implications for intervention. J Urban Health. 2007; in press.

46. Pridmore P, Thomas L, Haveman K, Sapag J, Wood L. Social capital and health urbanization in a globalized world. J Urban Health. 2007; in press.

47. Berkman LF, Glass T, Brissette I, Seeman TE. From social integration to health: Durkheim in the new millennium. Soc Sci Med. 2000;51(6):843-857.

48. Mullins LC, Elston CH, Gutkowski SM. Social determinants of loneliness among older Americans. Genet Soc Gen Psychol Monogr. 1996;122(4):453-473.

49. Marsella AJ. Urbanization, mental health, and social deviancy. A review of issues and research. Am Psychol. 1998;53(6):624-634.

50. Dohrenwend BP, Dohrenwend BS. Psychiatric disorders in urban settings. In: Caplan G, ed. Child and Adolescent Psychiatry: Sociocultural and Community Psychiatry. New York: Basic Books; 1974:424-449.

51. Andrulis DP. Community, service, and policy strategies to improve health care access in the changing urban environment. Am J Public Health. 2000;90(6):858-862.

52. United Nations Millennium Project. Earthscan. A Home in the City-Task Force on Improving the Lives of Slum Dwellers. United Nations; 2005. http://www.unmillennium project.org/reports/tf_slum.htm. Cited 26 February 2007.

53. Salmon JW, Whiteis DG. Improving public health care: lessons on governance from five cities. J Health Care Poor Underserved. 1992;3(2):285-304.

54. Plochg T, Delnoij DM, Hogervorst WV, van Dijk P, Belleman S, Klazinga NS. Local health systems in 21st century: who cares?-an exploratory study on health system governance in Amsterdam. Eur J Public Health. 2006;16:559-564.

55. Davis M. Planet of Slums. New York: Verso; 2006.

56. Menegat R. Atlas Ambiental de Porto Alegre. Brasilia: Universidade Federal do Rio Grande do Sul/Prefeitura Municipal de Porto Alegre/Insituto de Pesquisas Espaciais Brazil; 1998.

57. Follegatti JLL. Ilo: a city in transformation. Environ Urban. 1999;11(2):181-202.

58. Velásquez LS. Agenda 21; a form of joint environmental management in Manizales, Colombia. Environ Urban. 1998;10(2):9-36.

59. Burris S, Hancock T, Lin V, Herzog A. Emerging strategies for healthy urban governance. J Urban Health. 2007; in press. 
60. Mumford L. The City in History: Its Origins, Its Transformation, Its Prospects. New York: Harcourt, Brace \& Co.; 2006.

61. Freudenberg N. Public health advocacy to change corporate practices: implications for health education practice and research. Health Educ Behav. 2005;32(3):298-319.

62. Yach D, Hawkes C, Gould CL, Hofman KJ. The global burden of chronic diseases: overcoming impediments to prevention and control. JAMA. 2004;291(21):2616-2622.

63. Hordijk M. Participatory governance in Peru: exercising citizenship. Environ Urban. 2005;17(1):219-236.

64. Thomas SB, Quinn SC, Billingsley A, Caldwell C. The characteristics of northern black churches with community health outreach programs. Am J Public Health. 1994;84(4): 575-579.

65. Lincoln CE, Mamiya LH. The Black Church in the African American Experience. Durham: Duke University Press; 1990.

66. DeHaven MJ, Hunter IB, Wilder L, Walton JW, Berry J. Health programs in faith-based organizations: are they effective? Am J Public Health. 2004;94(6):1030-1036.

67. Burra S. Towards a pro-poor framework for slum upgrading in Mumbai, India. Environ Urban. 2005;17(1):67-88.

68. Lawrence RJ. Housing and health: beyond disciplinary confinement. J Urban Health. 2006;83(3):540-549.

69. Vlahov D, Galea S. Urbanization, urbanicity, and health. J Urban Health. 2002;79 (4 Suppl 1):S1-S12. 